\title{
Medically induced opioid addiction reaching alarming levels
}

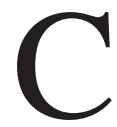

all it medically induced and law-abiding addiction. Experts says it's harder to kick than heroin and they're so astonished by its growing incidence that they're arguing for Canada to move immediately with a strategy to constrain its future effects on the health care system and the health of Canadians.

Prescription opioid addiction appears to have been dangerously underestimated, says Irfan Dhalla, a University of Toronto researcher and member of the advocacy group, Physicians for Responsible Opioid Prescribing, pointing to a recent study of 705 United States outpatients undergoing long-term opioid therapy for noncancer pain at Geisinger Health Centers, a health care system in Danville, Pennsylvania (J Addict Dis 2011;30:18594). It found that $21.7 \%$ met the standard criteria for moderate opioid-use disorder, while $13.2 \%$ met the criteria for severe opioid-use disorder.

Those staggering percentages have Dhalla and others calling on Ottawa to launch a coordinated national strategy on prescription opioid addiction as part of its revisions to the national antidrug strategy. "Health Canada and the federal government should be much more actively involved in efforts to reduce harm from prescription opioids," says Dhalla. "The FDA [Food and Drug Administration] and the White House in the US are doing much more than their counterparts in Canada. Health Canada could consider making changes to product monographs and even withdraw approval for formulations that routinely lead to doctors prescribing very high doses."

Benedikt Fischer, director of the Centre for Applied Research in Mental Health and Addiction at Simon Fraser University in Vancouver, British Columbia, wants the federal government to go even further, by making prescription opioid control "a central focus and component of a next iteration of a National Drug Strategy," or "the focus of its own specific strategy of interven-

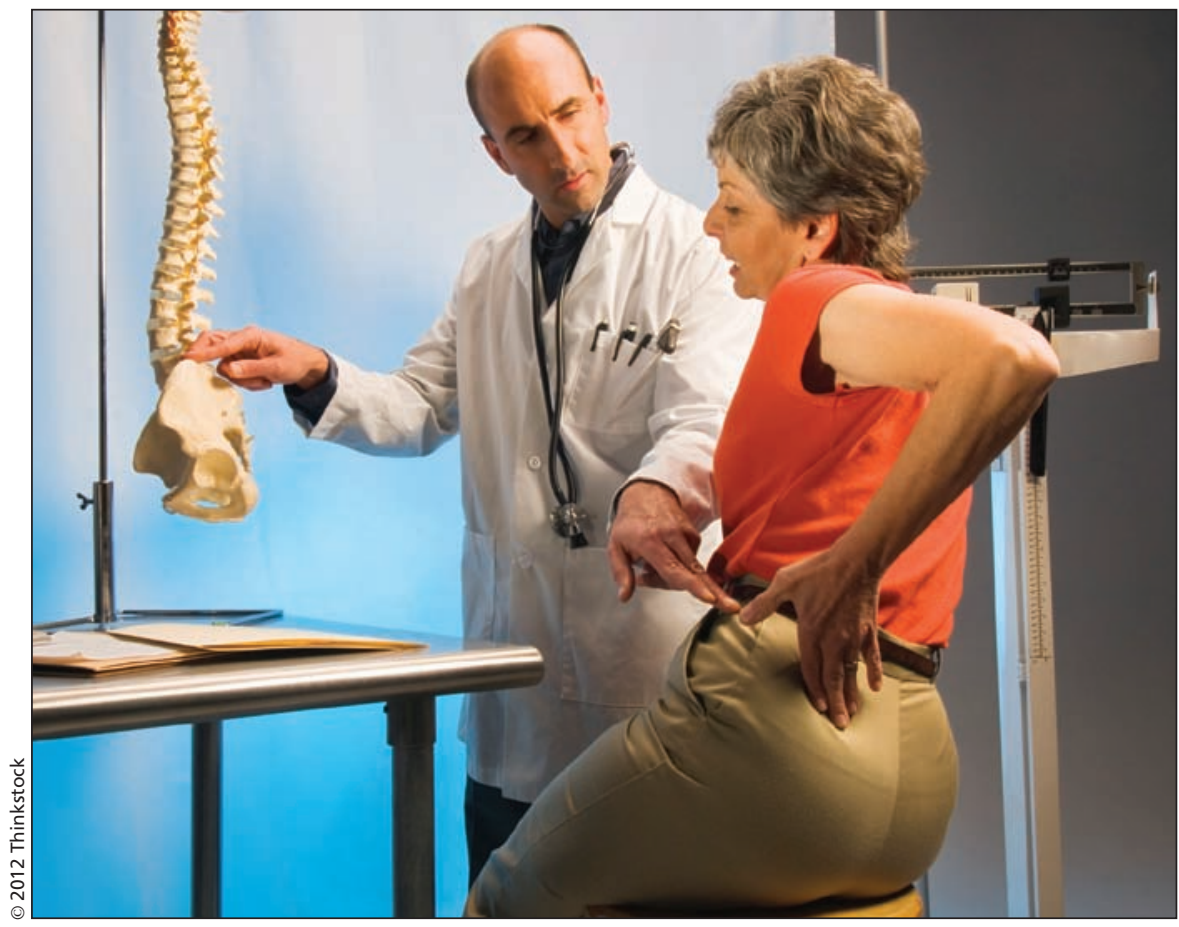

Researchers are concerned that vast numbers of "medically dependent" opioid addicts are being created simply by following doctors' orders.

tions and programs, allowing comprehensive and concerted action."'

Fischer and Jürgen Rehm, director of the Social and Epidemiological Research Department at the Centre for Addiction and Mental Health in Toronto, Ontario, warned the federal government in a recent report to the Department of Justice that Canada isn't doing enough to track opioid abuse or treat medically induced addiction.

Canadians are among the highest users of prescription opioid in the world, Fischer and Rehm say, adding that their report informed the government that overall usage of prescription opioids has more than doubled over the past decade.

While widespread use of illicit opioid use has been widely reported, the researchers say they are increasingly concerned that vast numbers of "medically dependent" addicts are being created simply by following doctors' orders. "I think it's fair to say that the number of patients who develop an addiction in Canada is sufficiently high that prescribers and public health authorities should be concerned," says Dhalla.

Joseph Boscarino, who led the Geisinger study, was surprised and alarmed to find that as many as one in five long-term noncancer patients using opioids develop moderate to severe dependency. "If you look at the demographics in our sample, this mostly involves older women living in suburban and rural areas," he says. "It's not your classic inner city-dwelling drug addict. These are people who are at potential risk [of addiction] but have never before been exposed to these drugs and are now getting exposed. And many of those who are at risk are going to succumb to the addiction."

The study has helped fill gaps in estimating the prevalence of prescription opioid abuse among primary care patients, says Michael Von Korff, a senior investigator with the Group Health Research Institute in Seattle, Washington. "These are old drugs but they haven't been widely studied. There 
hasn't been a lot of high quality research. But the word is now starting to get out."

"These are people getting opioids legally, from a physician. It's a significant problem," he adds, estimating that as many as one million of the eight million Americans using prescription opioids are now medically addicted - and perhaps twice that amount if the Geisinger study is accurate.

It's slowly forcing some painful soul searching in pain management circles, Von Korff says.

An educational video produced by Physicians for Responsible Opioid Prescribing includes information from a drug manufacturer asserting that "the rate of addiction amongst pain patients who are treated by doctors is much less than 1\%" (www.responsibleopioidprescribing .org/educational/index.html).
But that estimate "was a gross misinterpretation, not just by the manufacturer ... but by the so-called thought leaders who were in positions of eminence, and some of our professional organizations and the pain management community who allowed that myth to perpetuate itself by misinterpretation of those data," charges Nathaniel Katz, director of the Center for Opioid Research at the Massachusetts General Hospital, in Boston, Massachusetts.

Dhalla says there's no compelling reason to believe that medically induced addiction rates in Canada are dramatically different from those found in the US.

But Canadian data are sparse and inexact, says Rehm, who nearly a decade ago estimated that the number of illicit prescription drug users in Canada was between 300000 and 900000 (Can J Public Health 2009;100[2]:104-8)

As many as 200000 Canadians are currently addicted to painkillers, Rehm estimates, adding that he's equally discouraged that evidence-based best practices for treatment of medically induced addiction do not exist.

The doubling in the number of Ontarians seeking treatment for prescription opioid abuse since 2005 and the tripling in the number of patients now undergoing methadone treatment are indicators of troubles to come, he adds. "And we need to keep in mind that addiction to prescription opioids is a chronic relapsing disease." - Paul Christopher Webster, Toronto, Ont.

CMAJ 2012. DOI:10.1503/cmaj.109-4088

\section{Sex-selective abortions: no simple solution}

$\mathrm{W}$ hile American legislators contemplate criminalizing sex-selective abortion, experts say the experience of other nations which have tried to impose such a prohibition indicates that it is difficult to enforce and easy to skirt.

Nevertheless, United States Congressman Trent Franks (Arizona-Republican) is pushing to outlaw abortion for the purpose of sex or race selection. If passed, the Susan B. Anthony and Frederick Douglass Prenatal Nondiscrimination Act of 2011 will see health professionals who perform or accept funding for the taboo terminations face unspecified fines and imprisonment for up to five years. Anyone who coerces or transports a woman into the States to abort a fetus based on its race or gender will also be subject to penalty, although women who undergo the procedure are exempted from prosecution (www.opencongress .org/bill/112-h3541/text).

Franks says the need for a prohibition against sex selection is evident in the findings of a 2008 National Academy of Sciences report, which indicated that there has been a recent uptick in "son-biased sex ratios" among Asian immigrants to the United
States, suggesting significant "sex selection, most likely at the prenatal stage" (www.pnas.org/content/105 /15/5681.full). He also asserts that the ban is needed for race selection because minority babies are aborted at five times the rate of white babies.

"I hope that this bill will catalyze an awareness where people will begin to recognize the humanity of the victims and the inhumanity of what's being done to them," he says.

Similar policies have been enacted in the last three decades to offset dire gender imbalances in India, China and South Korea, among other countries. But these strategies - which include restricting access to sex-selective abortion and banning sex detection tests have been difficult to enforce and have had limited efficacy.

Opponents argue that such legislative approaches are unnecessary and ineffective.

Such policies are being used to "create insidious new obstacles to reproductive healthcare" and "do not in any way address the serious and complex concerns raised by the practice of sex selection," Sujatha Jesudason, executive director of Generations
Ahead, stated in the pro-choice organization's official Statement opposing sex selection bill (www.generations -ahead.org/files-for-download/success -stories/Statement_12_5_11.pdf). "This bill means just one thing for every woman: the highest and most intrusive of scrutiny of the reason she seeks an abortion."

Franks does not take issue with the assertion that there is a "bigger agenda" behind the bill. "I do hope that someday children of all sexes and races will be protected from abortion on demand," he admits.

But he believes sex-selective abortion is a unique opportunity for advocates on both sides of the abortion debate to find common ground. "We may not agree on abortion, but at least we can say as a society that we're not going to abort children based on the fact that they're the wrong colour, or that they're a girl or boy."

Criminalizing the practice, however, may not be the best way to achieve that objective. The imbalance in India's male-to-female sex ratio at birth has steadily worsened since the country introduced its ban on sex-selective abortion in 2003, following a ban on 